\title{
Tahap Perencanaan Media Pembelajaran Komik Strip Abah Umis Pada Materi Kausa Materialis Pancasila
}

\author{
Wan Ridwan Husen'1, Arni Apriani', Fajar Nugraha ${ }^{2}$ \\ 'Prodi Sendratasik, Universitas Muhammadiyah Tasikmalaya, Jl. Tamansari Km 2,5 Kota Tasikmalaya \\ ${ }^{2}$ Prodi PGPAUD, Universitas Muhammadiyah Tasikmalaya, Jl. Tamansari Km 2,5 Kota Tasikmalaya \\ Correspondence Email: wanridwanhusen@gmail.com
}

\begin{abstract}
Abstrak
Tulisan ini bertujuan untuk memberikan gambaran dari salah satu tahapan dalam membuat komik strip sebagai media pembelajaran menggunakan metode $4 \mathrm{~d}$, focus tulisan ini adalah langkah kedua setelah melakukan tahap desain (Perancangan), yaitu tahap perancangan (design) dari media pembelajaran komik strip yang dibuat, pembahasan dalam tahap perencanaan ini terdapat beberapa tahap diantaranya penyusunan Tes (criterion-test construction) kemudian bagaimana pemilihan Media (media selection) lalu pemilihan Format (format selection) dan desain Awal (initial design). Tujuan dari penelitian "Pengembangan Komik Strip Abah Umis Sebagai Media Pembelajaran Materi Kausa Materialis Pancasila” ini adalah untuk Mengembangkan komik Strip Abah Umis sebagai media pembelajaran pada materi Kausa Materialis Pancasila. Komik strip Abah Umis ini dirancang sebagai media pembelajaran yang diharapkan dapat menumbuhkan kesadaran mahasiswa terhadap pancasila, dengan mengenal bagaimana asal usul Pancasila khususnya materialis kausa Pancasila maka diharapkan dapat diaplikasikan dalam kehidupan sehari-hari. Penelitian ini menggunakan pendekatan kuantitatif, Metode yang digunakan dalam penelitian ini adalah penelitian dan pengembangan. Model pengembangan dalam media pembelajaran ini menggunakan model pengembangan 4-D (Four D), artikel ini di fokuskan pada tahapan awal yaitu tahap perencanaan untuk model pengembangan media pembelajaran, Subjek penelitian ini yaitu mahasiswa yang mengontrak mata kuliah PKN di UMTAS (Universitas Muhammadiyah Tasikmalaya).

Kata Kunci:

Media pembelajaran; Komik Strip; kausa materialis Pancasila
\end{abstract}

\begin{abstract}
This paper is the second step after carrying out the design stage, namely the design stage of the comic strip learning media that is made, the discussion in this planning stage there are several stages including the preparation of tests (criterion-test construction) then how to select the media (media selection) then choose Format (format selection) and Initial design. The purpose of the research "The Development of Abah Umis Comic Strips as Learning Media for Pancasila Causa Materialis Material" is to develop the Abah Umis comic strip as a learning medium on the material for Causa Materialis Pancasila. This Abah Umis comic strip is designed as a learning medium that is expected to raise students' awareness of Pancasila, by knowing how the origin of Pancasila, especially materialis kausa Pancasila, is expected to be applied in everyday life. This study uses a quantitative approach. The method used in this research is research and development. The development model in this learning media uses the 4-D (Four D) development model, this article is focused on the initial stages, namely the planning stage for the learning media development model, the subjects of this research are students who contract PKN courses at UMTAS (Universitas Muhammadiyah Tasikmalaya).
\end{abstract}

Keywords:

Learning media; Comic Strips; Pancasila materialist causes 


\section{Pendahuluan}

Tulisan ini bertujuan untuk memberikan gambaran dari salah satu tahapan dalam membuat komik strip sebagai media pembelajaran menggunakan metode 4d. Pembelajaran kausa materialis Pancasila di kampus Universitas Muhammadiyah Tasikmalaya (UMTAS) merupakan salah satu rangkaian dari materi pada mata kuliah PKN yang diselenggarakan kampus sebagai mata kuliah wajib tingkat universitas, tujuan dari materi kausa materialis pancasila adalah salah satu upaya dalam membangun kesadaran mahasiswa guna memahami dan mencintai Indonesia.

UMTAS merupakan kampus homebase peneliti yang mempunyai tiga fakultas dengan latar belakang yang berbeda, dimana disana terdapat FKIP (Fakultas keguruan dan Ilmu Pendidikan), FKES (Fakultas Kesehatan), dan FT (Fakultas Teknik) sebagai bahan kajian peneliti. Media komik ini diharapkan bisa menarik minat belajar, karena dalam fisiknya komik bisa masuk kesemua latar pendidikan dan lintas usia, besar harapan dengan dibuat media komik ini diharapkan semua mahasiswa memiliki pemahamanan secara holistic dan efektif dalam memahami Indonesia secara menyeluruh, khususnya pada mata kuliah PKN pada materi Kausa Materialis Pancasila.

Pada dasarnya media pembelajaran merupakan hal yang mendukung sebuah pembelajaran menjadi lebih baik. Karena media pembelajaran ini dibuat berdasarkan kebutuhan dosen dan mahasiswa, maka capaian dari dibuatnya media ini diharapkan menjadi sebuah daya tarik dalam proses pembelajaran yang dilakukan.

Setelah mendapatkan permasalahan dari tahap pendefinisian, maka Langkah selanjutnya dilakukan tahap perancangan. Tahap perancangan ini bertujuan untuk merancang suatu media yang akan digunakan dalam proses pembelajaran PKN di Universitas Muhammadiyah Tasikmalaya. Tahapan perancangan pada penelitian ini dilakukan untuk membuat kerangka atau arah dari dibuatnya sebuah media yang sesuai dengan kerangka isi hasil tahapan pendefinisian yang telah dilakukan sebelumnya.

\section{Hasil dan Pembahasan}

\subsection{Perencanaan Media Pembelajaran Komik Strip}

Tahap perancangan dalam pembuatan media pembelajaran ini dilakukan untuk merancang bagaimana media pembelajaran berbentuk komik strip dengan materi asal usul pancasila. Pada tahap ini dibuat rancangan media yang akan diuji cobakan kepada peserta didik dalam hal ini mahasiswa yang mengontrak mata kuliah PKN di UMTAS. Adapun Tahap perancangan ini meliputi beberapa Langkah diantaranya: Langkah yang pertama merupakan Penyusunan Tes (criterion-test construction), kemudian kepada Pemilihan Media (media selection), dilanjutkan dengan Pemilihan Format (format selection), dan sampai pada Desain Awal (initial design) untuk dibuat sebuah media berupa komik strip.

Langkah dari Penyusunan Tes (criterion-test construction) merupakan tindakan pertama untuk mengetahui kemampuan awal peserta didik, penyusunan tes dalam media pembelajaran ini berfungsi juga sebagai alat evaluasi setelah dilakukan implementasi pembelajaran PKN yang menggunakan media pembelajaran komik strip ini. Penyusunan tes ini dilakukan dengan 
wawancara dan diskusi dengan mahasiswa dan dosen PKN yang telah melakukan pembelajaran kausa materialis Pancasila, kemudian dikembangkan untuk bagaimana media tersebut bisa efektif dan diterima dengan mudah oleh mahasiswa.

Kemudian Langkah berikutnya adalah dilakukannya Penyusunan tes instrumen dimana dibuat berdasarkan tujuan dari pembelajaran dengan melihat draft Rancangan pembelajaran semester (RPS) yang menjadi tolak ukur untuk melihat kemampuan peserta didik dalam hal ini mahasiswa UMTAS, selain dari meninjau bagaimana sebaiknya media jika dibuat dalam bentuk produk komik strip, kemudian meninjau proses pembelajaran yang dilakukan menggunakan komik strip, kemudian mengetahui bagaimana respon dari mahasiswa baik ketika proses maupun setelah kegiatan pembelajaran berlangsung.

Pada penelitian ini Langkah Pemilihan Media (media selection) dilakukan untuk mengidentifikasi media pembelajaran yang relevan dengan karakteristik mahasiswa dan materi yang akan disampaikan juga sesuai dengan kebutuhan peserta didik dalam efektifitas dalam penyampaian materi. Dikatakan dalam sebuah kutipan "... bahwa media pembelajaran adalah segala bentuk dan sarana penyampaian informasi yang dibuat atau digunakan sesuai dengan teori pembelajaran, dapat digunakan untuk tujuan pembelajaran dalam menyalurkan pesan merangsang pikiran, perasaan perhatian dan kemauan siswa sehingga dapat mendorong terjadinya proses belajar yang disengaja bertujuan dan terkendali. (Suryani 2018:5) hal ini dikatakan juga oleh Arsyad (2009:4) bahwa "media pembelajaran sebagai media yang membawa pesan atau informasi yang bertujuan instruksional atau mengandung maksud pengajaran". Kemudian disampaikan oleh Widayanti yang mengatakan dalam sebuah artikel. "Oleh karena itu dapat dikatakan bahwa pengajaran melalui komik merupakan media pengajaran yang komunikatif pada pengajaran sastra karena melalui komik mahasiswa dapat lebih memahami teks narasi dan menganalisa elemen-elemen prosa yang ada di dalamnya baik dari sisi intrinsik maupun ekstrinsiknya".

Kemudian dilanjutkan kepada Pemilihan Format (format selection), agar format yang dipilih sesuai dengan arah dari materi pembelajaran. Pemilihan bentuk penyajian disesuaikan dengan media pembelajaran yang telah dikonsultasikan dosen pengampu PKN guna tidak kehilangan arah atau keluar dari jalur tujuan pembelajaran itu sendiri. Pemilihan format dalam pengembangan dimaksudkan dengan mendesain isi pembelajaran, pemilihan pendekatan, dan sumber belajar, mengorganisasikan dan merancang isi komik, membuat desain komik, yang meliputi desain layout, gambar, dan tulisan.

Sebelum dicetak dalam jumlah banyak maka Desain awal (initial design) yang merupakan rancangan media komik yang telah dibuat oleh peneliti kemudian diberi masukan oleh tim ahli dimana dilakukan konsultasi dengan illustrator dan desainer, Masukan dari tim ahli akan digunakan untuk memperbaiki, merevisi atau mengganti isi dari media komik sebelum dilakukan produksi dalam skala banyak.

Pada proses pembuatan komik strip ini dilakukan langkah-langkah yang mendukung proses pembuatan media pembelajaran ini agar efektif baik apabila dipakai oleh dosen dalam pengajaran maupun media alternatif belajar kausa materialis Pancasila secara mandiri oleh mahasiswa, Adapun Langkah-langkah yang ditempuh dalam membuat komik strip 
adalah sebagai berikut: (1) menentukan ide cerita kemudian (2) menentukan tampilan untuk digunakan sebagai media pembelajaran, (3) menyusun karakter tokoh, (4) storyBoard, (5) proses komputer, dan pada akhirnya melalui proses(6) pencetakan dan penjilidan agar karya yang telah dikumpulkan bisa didaftarkan ISBN serta didaftarkan HKI guna kebutuhan karir dari peneliti.

Dalam menentukan ide cerita gagasan berupa gambar sederhana kemudian dibuat komik strip dengan capaian akhir adalah tersampaikannya materi secara cepat dan efektif merupakan hal yang menjadi bahan pertimbangan utama, selain agar mudah dipahami, komik strip ini dibuat sesuai dengan minat anak muda karena mahasiswa sebagai generasi muda yang merupakan sasaran dari konsumen komik ini.

Kemudian dalam menentukan tampilan dalam komik sebagai media pembelajaran merupakan hal yang menjadi prioritas untuk dikonsultasikan kepada tim ahli, dalam hal ini terdapat beberapa sumber diantaranya seorang ilustrator, desainer, kemudian dosen PKN guna menyesuaikan kebutuhan materi dengan komik yang akan dibuat.

Dalam menyusun karakter tokoh utama yaitu seorang abah umis dalam komik ini merupakan tokoh yang berperan sebagai tokoh satu-satunya atau disebut dengan komik monolog sehingga tidak diperlukannya tokoh atau pemeran lain dalam komik strip ini, layaknya bagaimana ketika seorang pengajar atau pengajar menjelaskan sebuah materi.

Proses pembuatan story Board merupakan hal yang penting dalam sebuah komik, karena akan sangat menentukan alur baca dan menentukan bagaimana penjelasan dapat mudah untuk dipahami oleh pembaca yang difokuskan kepada mahasiswa. Langkah berikutnya adalah proses komputer yang merupakan proses pemindahan sketsa pensil kemudian telah melalui proses inking untuk menebalkan outline gambar komik, kemudian dipindahkan ke komputer untuk melalui tahap pewarnaan atau coloring sehingga komik yang dihasilkan merupakan komik berwarna guna menarik perhatian pembaca. Layout komposisi komik juga dilakukan melalui media komputer agar mempermudah penyusunan panel dalam komik ini.

Karena permintaan dari dosen yang bersangkutan agar dibuatkan ke dalam bentuk cetak atau dengan bentuk buku, yaitu berupa kumpulan komik strip yang di cetak ke dalam sebuah buku, sehingga tahap berikutnya adalah tahap pencetakan dan penjilidan, yang kemudian akan diajukan ISBN dan HKI dari kumpulan karya tersebut.

Perbaikan dengan pedoman saran dari tim ahli dilakukan guna dijadikan bahan revisi berupa ilustrasi untuk kemudian media komik di didiskusikan dengan dosen PKN itu sendiri sebagai bahan pertimbangan tepat atau kurang tepat sasaran nya materi yang telah dibuat. nantinya rancangan ini akan dilakukan tahap validasi. Rancangan ini berupa draft dari media komik.

\subsection{Komik Strip Abah Umis}

Abah umis sebagai figure yang digambarkan seorang pendidik atau pemberi informasi diharapkan menjadi jembatan guna kebutuhan media dalam transfer ilmu, dalam hal ini bagaimana komik akan menjadi sebuah wadah abah umis berbagi materi bahan ajar kepada pembacanya dalam hal ini tentu mahasiswa. 
Dengan melihat ketertarikan mahasiswa terhadap media komik strip yang menyenangkan dan ringan untuk dipelajari dalam keseharian mereka, maka komik strip ini diharapkan menjadi media yang tepat untuk dipelajari atau dibaca di waktu luang mereka.

Komik strip yang dijadikan media pembelajaran ini merupakan sebuah gagasan bagaimana membuat media pembelajaran yang unik agar diminati oleh peserta didik dalam hal ini khususnya mahasiswa. Menurut Scott McCloud (1993) "komik adalah gambar-gambar dan lambang-lambang lain yang terjukstaposisi (saling berdampingan) dalam urutan tertentu, bertujuan untuk memberikan informasi dan atau mencapai tanggapan estetis dari pembaca."

Komik strip merupakan komik yang singkat dibanding komik kebanyakan, biasanya hanya terdiri dari empat panel gambar, Menurut Maharsi (2010) dalam Yusuf (2016), bentuk komik dibagi menjadi 5 kategori, yaitu Komik Strip, Buku Komik, Novel Grafis, Komik Kompilasi dan Webcomic.

Dalam hal ini karakter Abah Umis dibuat dalam bentuk komik strip, dimana kelebihan yang dimiliki komik strip ini adalah komik yang singkat biasanya ditampilkan dalam satu lembar kertas atau tampilan sebagai upaya dalam penyampaian materi kausa materialis Pancasila dengan ringkas.

Septiawan menyatakan bahwa "Sebuah media berbasis komik strip berisi tentang sifat dasar yang seharusnya dimiliki seorang anak, seperti tenggang rasa, saling menghargai dan menghormati serta nilainilai kebhinekaan dipilih sebagai panduan untuk anak-anak, mengingat buku komik merupakan sebuah hiburan yang digemari oleh anak-anak".

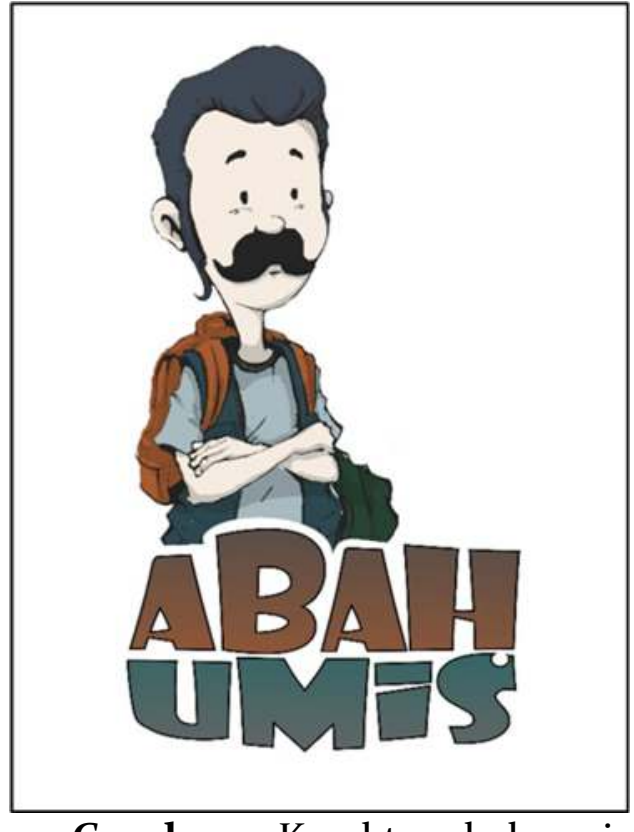

Gambar 1. Karakter abah umis Sumber: Dokumentasi pribadi

Karakter Abah Umis merupakan tokoh fiktif yang berasal dari semacam alterego seorang pengajar, yang dibuat melalui karya-karya drawing peneliti sebagai hobi dalam kesehariannya, biasanya dibuat sebagai penanda perjalanan atau rekam jejak yang dituangkan dalam karya ilustrasi perjalanan seorang Wan Ridwan.

Gagasan karakter Abah Umis yang berperan sebagai seorang pengajar dijadikan media pembelajaran dalam hal ini difokuskan kepada materi kausa materialis pancasila yang terdapat dalam materi di mata kuliah PKN. Kedepannya figure abah umis ini akan dikembangkan menjadi bentuk animasi atau film pendek jika memang layak dijadikan sebagai media pembelajaran.

Sosok Abah Umis ini digambarkan dengan seorang pria berusia matang berkumis tebal dengan pakaian seperti seorang petualang dan pengajar, dimana seorang yang berfungsi dalam mengajar dan berpetualang yang terjun langsung ke tempat dimana materi tersebut dibahas. 
Abah Umis merupakan figur yang terinspirasi dari tokoh-tokoh filsuf masa lalu dimana dalam fisiknya mempunyai ciri khas dengan tampilan kumis yang tebal .

\section{Simpulan}

Ketika komik strip abah umis dijadikan media pembelajaran maka perlu penanganan yang serius terutama dalam hal riset mengenai bagaimana kehadiran media alternatif selain buku ajar yang digunakan dalam efektifitas penyampaian materi dari sisi media untuk tujuan pembelajaran. Tulisan ini merupakan tahap desain (Perancangan) dari media pembelajaran komik strip yang telah dibuat untuk diuji cobakan kepada mahasiswa dalam proses pembelajarannya, dimana sebelumnya telah melakukan bagaimana tahap define (pendefinisian), yang mana langkah berikutnya merupakan tahap yang akan dilakukan berupa tahap develop (pengembangan) dan disseminate (penyebaran). Maka sebagai kesimpulan diperoleh Langkah langkah dalam penelitian ini sebagai berikut (1) penyusunan Tes (criterion-test construction) kemudian bagaimana (2) pemilihan Media (media selection) lalu (3) pemilihan Format (format selection) dan (4) desain Awal (initial design).

Pada akhirnya adalah ketika semakin berkembangnya zaman maka ada baiknya pengajar memanfaatkan situasi dengan cerdas, dengan mengikuti minat mahasiswa agar dengan senang hati menyerap informasi dengan mengikuti kebiasaan mereka yang setiap saat membuka hp hanya sekedar men scroll timeline di sosial media. Seiring perkembangan media informasi seperti media sosial, komik strip banyak muncul sebagai hiburan dan media kritik satire mengenai banyak persoalan, selain dari kesederhanaan sebuah karya yang fungsional, komik strip juga banyak disukai oleh kalangan muda dalam hal ini mahasiswa, munculnya komik strip ini juga menjadi penyegar dari kreatifitas banyak kalangan muda dalam menyalurkan aspirasi mereka.

\section{Daftar Pustaka}

Arsyad, Azhar. (2013). Media Pembelajaran. Jakarta: Raja Grafindo Persada.

Daryanto. (2010). Media Pembelajaran Peranannya Sangat Penting Dalam Mencapai Tujuan Pembelajaran. Yogyakarta: Gava Media.

Jazuli, Prof. Dr. M,Hum. (2008). Paradigma Kontekstual Pendidikan Seni, Penerbit Unesa University Press, Semarang.

Kustandi, Cecep. (2013). Media Pembelajaran Manual dan Digital. Bogor: Ghalia Indonesia.

McCloud, Scott. (1993). Understanding Comics. the Invisible Art.

Susilana, Rudi dan Cepi Riyana. ( 2007). Media Pembelajaran: Hakikat, Pengembangan, Pemanfaatan, dan Penilaian. Bandung: CV Wacana Prima

Ratnawuri, Triani. (2016). Pemanfaatan Komik Strip Sebagai Media Pembelajaran Mahasiswa Pendidikan Ekonomi Um Metro, Jurnal Pendidikan Ekonomi UM Metro Vol.4. No.2 8-12

Septiawan, Stefanus,( 2019). Perancangan Komik Strip Bagi Anak-Anak Usia 7-12 Tahun Untuk Menumbuhkan Rasa Persatuan Dan Kesatuan Berlandaskan Bhinneka Tunggal Ika, Artika Volume.4, Nomor.1, Juli 2019. ISSN 2355-8121, EISSN 2549-7251 
704 | Naturalistic: Jurnal Kajian Penelitian dan Pendidikan dan Pembelajaran, Volume 5 Issue 1, Oktober 2020 Hal 698-704

Suryani, Nunuk, Prof. Dr. (2018). Media Pembelajaran inovatif dan Pengembangannya. PT Remaja Rosdakarya. Bandung

Widayanti, Maria J. A. (2012). Komik Sebagai Media Pengajaran Untuk Meningkatkan Pemahaman Mahasiswa Terhadap Narasi Cerita, Lembaran Ilmu Kependidikan. Volume 41. Nomor 2. September
Yusuf, Raka. (2016). Aplikasi Berbasis Web Dengan Menggunakan Pustaka Javascript Fabricjs Untuk Pembuatan Komik Strip Punakawan, Seminar Nasional Teknologi Informasi dan Multimedia 2016 STMIK AMIKOM Yogyakarta, 6-7 Februari 